\title{
Estimation and Correlation of Different Hemoglobin Levels in HbE Hemoglobinopathies in Indian Population Using Capillary Electrophoresis Method
}

\author{
Abhijit Kalita ${ }^{1 *}$ and Avinanda Mahanta ${ }^{2}$ \\ ${ }^{1}$ Department of pathology, Pathcare Labs Pvt. Ltd., Hyderabad, India. \\ ${ }^{2}$ Department of Biochemistry, Guwahati Medical College Hospital, Guwahati, India
}

\begin{abstract}
Background: Capillary electrophoresis (CE) estimates Hemoglobin E (HbE) in HbE hemoglobinopathies, which was previously not possible with other method due to combined elution of $\mathrm{HbA} 2$ with $\mathrm{HbE}$. Associated hemoglobin abnormalities can be estimated with separation of $\mathrm{HbA} 2$ from $\mathrm{HbE}$.

Methods: The study is retrospective using $\mathrm{CE}$ to detect abnormal $\mathrm{HbE}$ and differentiate the HbE syndromes. Student t-test was used for statistical analysis.

Result: 119 cases of $\mathrm{HbE}$ syndromes were identified and divided into HbE heterozygotes (71), HbE heterozygotes with borderline HbA2 (15), compound heterozygotes of $\mathrm{HbE}$ with Thalassemia (13 HbE with $\beta$-Thalassemia / $8 \mathrm{HbE}$ with $\alpha$-Thalassemia), compound heterozygotes of $\mathrm{HbE}$ with $\mathrm{HbS}$ (HbSE) (2) and HbE homozygotes (10). Mean HbA2 shows increasing pattern with increasing severity of HbE syndrome. However, compound heterozygote of $\mathrm{HbE}$ and $\beta$-Thalassemia (HbE- $\beta$-Thal) shows maximum mean level of $\mathrm{HbA} 2(5.46 \%)$. HbA2 of $\mathrm{HbE}$ heterozygote and $\mathrm{HbE}$ heterozygote with borderline $\mathrm{HbA} 2$ was not found to be significantly different, statistically. Fetal haemoglobin (HbF) of $\mathrm{HbE}$ homozygotes is found significantly higher than that of $\mathrm{HbE}$ heterozygotes, but significantly lower than that of HbE-Thalassemia. The $\mathrm{HbE}$ values of $\mathrm{HbE}$ with $\alpha$-Thalassemia (HbE- $\alpha$-Thal) and $\mathrm{HbE}-\beta$-Thal were found to be below $-3 \mathrm{SD}$ value $(14.77 \%)$ and beyond $+3 \mathrm{SD}$ value (37.77\%) of mean of $\mathrm{HbE}$ of $\mathrm{HbE}$ heterozygote $(26.27 \%)$, respectively.
\end{abstract}

Conclusion: The study identifies range of different hemoglobin levels in HbE syndromes, with special reference to HbA2. Concurrent iron deficiency anaemia also needs to be kept in mind in dealing with a population where iron deficiency is very common.

\section{Keywords: Capillary Electrophoresis, Hemoglobin E heterozygote, Hemoglobin E}

\section{Introduction}

Hemoglobin E ( $\mathrm{HbE}$ ) was the fourth abnormal hemoglobin described ${ }^{(1)}$. $\mathrm{HbE}$ is the second most prevalent hemoglobinopathy after Sickle cell hemoglobinopathy (HbS), showing the highest prevalence in South-East Asia (2). In India, it is prevalent in the north-eastern states ${ }^{(2,3,4,5)}$. Heterozygosity and homozygosity of $\mathrm{HbE}$ are clinically mild, whereas compound heterozygosity for $\mathrm{HbE}$ and $\mathrm{HbS}(\mathrm{HbSE})$ and compound heterozygosity for $\mathrm{HbE}$ and $\beta$-Thalassemia (HbE- $\beta$-Thal) are clinically severe ${ }^{(3,6,7,8,9)}$. The co-inheritance of $\mathrm{HbE}$ with a host of other globin mutants results in a wide spectrum of hemoglobinopathies with varying degrees of severity $(\mathrm{HbE}$ disorders or $\mathrm{HbE}$ syndromes) ${ }^{(1,10)}$.

All the methods used previously were not able to distinguish between $\mathrm{HbE}$ and $\mathrm{HbA}_{2}$. While reverse phase HPLC has been reported to provide an estimate of $\mathrm{HbA}_{2}$ in the presence of $\mathrm{HbE}$, this method is not routinely used in clinical laboratories ${ }^{(11)}$.

Capillary electrophoresis (CE) has the ability to completely separate $\mathrm{HbA}_{2}$ from $\mathrm{HbE}{ }^{(12,13,14)}$. This enables to quantitate exact levels of $\mathrm{HbE}$ and $\mathrm{HbA}_{2}$, assisting in identification of co-inherited hemoglobinopathies.

The present study is conducted to identify levels of different hemoglobins in $\mathrm{HbE}$ syndromes and to find their correlation, if any. Most of the studies conducted previously on hemoglobinopathies in the Indian population have highlighted the increased prevalence of $\mathrm{HbE}$ and associated syndromes. This study attempts to define the range of abnormality in the $\mathrm{HbE}$ syndromes.

\section{Materials and Methods :}

The present study is a retrospective study conducted for a period of one year (June 2015 to May 2016). Capillary electrophoresis method was used for identification of abnormal hemoglobin variants. Patients with abnormal 
$\mathrm{HbE}$ peaks and without any treatment history (particularly of blood transfusion) were included in the study, to have an accurate estimation of the hemoglobin levels. Cases with abnormal hemoglobin E peaks were correlated with the Complete blood count (CBC) and peripheral blood smear (stained with Leishman's stain) to conclude a final diagnosis. Cases were classified as $\mathrm{HbE}$ heterozygotes, $\mathrm{HbE}$ homozygotes and compound heterozygotes of $\mathrm{HbE}$ with other hemoglobinopathies (like sickle cell and Thalassemia). Another category, $\mathrm{HbE}$ with borderline $\mathrm{HbA}_{2}$, was classified in the present study, to find out if any significance exists. The mean values of $\mathrm{HbA}_{2}$ were compared statistically (using student t-test) amongst the $\mathrm{HbE}$ categories / syndromes, and also with control group of 30 normal individuals and $30 \beta$-Thalassemia cases.

\section{Result}

A total of 119 cases of $\mathrm{HbE}$ syndromes were identified during the study period, out of which 71 were $\mathrm{HbE}$ heterozygotes, 15 were $\mathrm{HbE}$ heterozygotes with borderline $\mathrm{HbA}_{2}, 21$ were compound heterozygotes of $\mathrm{HbE}$ with Thalassemia (13 with $\beta$-Thalassemia and 8 with $\alpha$-Thalassemia), 2 were compound heterozygotes of $\mathrm{HbE}$ with $\mathrm{HbS}$ and 10 were $\mathrm{HbE}$ homozygotes. The distribution of the cases into the different categories, along with levels of $\mathrm{HbA}_{2}$ are shown in Table 1.

On statistical analysis, there was no significant difference ( $p$-value $>0.05$ ) between the mean value of $\mathrm{HbA}_{2}$ in $\mathrm{HbE}$ heterozygotes, $\mathrm{HbE}$ heterozygotes with borderline $\mathrm{HbA}_{2}$, and normal control group. The mean of $\mathrm{HbA}_{2}$ in

Table 1: $\mathrm{HbA}_{2}$ levels in different $\mathrm{HbE}$ syndromes.

\begin{tabular}{|c|l|c|}
\hline SI no. & Type of HbE (with total number of cases) & HbA $_{2}$ level(\%)(Mean, \pm 2 SD) \\
\hline 1 & HbE heterozygote $(71)$ & $2.98, \pm 0.8$ \\
\hline 2 & HbE heterozygote with borderline $\mathrm{HbA}_{2}(15)$ & $3.76, \pm 0.31$ \\
\hline 3 & Compound heterozygote of HbE with $\beta$ - Thalassemia (13) & $5.46, \pm 2.48$ \\
\hline 4 & Compound heterozygote of HbE with $\alpha$ - Thalassemia (08) & $3.10, \pm 1.64$ \\
\hline 5 & Compound heterozygote of HbE with HbS (2) & $3.1, \pm 0.56$ \\
\hline 6 & HbE homozygotes (10) & $3.52, \pm 2.0$ \\
\hline
\end{tabular}

Table 2: Fetal haemoglobin (HbF) level in HbE syndromes

\begin{tabular}{|c|l|c|}
\hline SI no. & Type of HbE (with total number of cases) & HbF level(\%)(Mean, $\pm 2 S D)$ \\
\hline 1 & HbE heterozygote (71) & $0.48, \pm 1.68$ \\
\hline 2 & HbE heterozygote with borderline HbA $(15)$ & $0.36, \pm 1.28$ \\
\hline 3 & Compound heterozygote of HbE with beta-Thalassemia (13) & $19.71, \pm 26.60$ \\
\hline 4 & Compound heterozygote of HbE with alfa-Thalassemia (8) & $9.28, \pm 7.84$ \\
\hline 5 & Compound heterozygous of HbE and HbS (2) & $4.9, \pm 6.50$ \\
\hline 6 & HbE homozygotes (10) & $5.41, \pm 6.17$ \\
\hline
\end{tabular}




\section{Discussion}

The CE method allows detection and separation of most of the common hemoglobin variants ${ }^{(15,16)}$. The complete separation of $\mathrm{HbA}_{2}$ from $\mathrm{HbE}$ deserves note ${ }^{(17)}$.

The data obtained from 117 cases shows an increasing trend of the level of $\mathrm{HbA}_{2}$ in the $\mathrm{HbE}$ syndromes with increased severity of $\mathrm{HbE}$. However, the level of $\mathrm{HbA}_{2}$ in $\mathrm{HbE}-\beta$-Thal is significantly higher than all other categories, including $\mathrm{HbE}$ homozygous. This trend is similar to the study conducted by Mais DD et $a l^{(6)}$, but the significant increased level of $\mathrm{HbA}_{2}$ seen in $\mathrm{HbE}$ heterozygotes compared with that of normal control group in the study of Mais DD et al ${ }^{(6)}$, is not seen in the present study. Morever, the category defined in this study " $\mathrm{HbE}$ with borderline $\mathrm{HbA}_{2}$ " also does not have significant difference of $\mathrm{HbA}_{2}$ level from the normal control and $\mathrm{HbE}$ heterozygous categories. The study conducted by Keren DF et al ${ }^{(17)}$ suggested that the levels of $\mathrm{HbA}_{2}$ are over - estimated by capillary electrophoresis method but the study also argues that in $\mathrm{HbE}$ syndromes, relative increase in $\mathrm{HbA}_{2}$ levels is expected, because $\mathrm{HbE}$ is a structural form of beta - Thalassemia. The range defined for $\mathrm{HbA}_{2}$ for $\mathrm{HbE}$ heterozygotes in the present study (Table 1 ) is lower than that described by Mais DD et al ${ }^{(6)}$ (Mean $\pm 2 \mathrm{Sd}, 3.4 \% \pm 0.4 \%$ ) and Winichagoon $\mathrm{P}$ et al ${ }^{(18)}$ (Mean \pm $2 \mathrm{SD}, 3.5 \% \pm 0.4 \%$ ). However, the range of $\mathrm{HbA}_{2}$ defined for $\mathrm{HbE}$ heterozygous with borderline $\mathrm{HbA}_{2}$ is found to be in comparison with the mentioned studies. This can be attributed to concurrent iron deficiency anaemia, particularly in the Indian population, which lowers the levels of $\mathrm{HbA}_{2}$, as evidenced by studies of Rao $\mathrm{S}$ et al ${ }^{(19)}$ and Denic $\mathrm{S}$ et al ${ }^{(20)}$.

The fetal hemoglobin ( $\mathrm{HbF}$ ) of $\mathrm{HbE}$ homozygotes is found to be significantly higher than that of $\mathrm{HbE}$ heterozygotes, but significantly lower than that of $\mathrm{HbE}$ - Thal. The level of $\mathrm{HbF}$ inversely correlate well with proportion of $\mathrm{HbA}$ in the haemoglobin variant. In $\mathrm{HbE}$ homozygous, however, the $\mathrm{HbE}$ levels lowers the $\mathrm{HbF}$ levels, inspite of low HbA level (Mean $\mathrm{HbA} 7.4 \%$ ). HbF is affected significantly by alfa / Beta - globin chain imbalances, as evidenced by study of Lin WF et al ${ }^{(21)}$

The mean of $\mathrm{HbE}$ levels of $\mathrm{HbE}$ heterozygote in the present study was found to be $26.27 \% \pm 7.6 \%$ (Mean $\pm 2 \mathrm{SD}$ ) which is in comparison with the study of Charoenkwan $\mathrm{P}$ et al ${ }^{(22)}$ $(23.3 \% \pm 6.2 \%)$ and Hafiza A et al ${ }^{(23)}(24.28 \% \pm 6.76 \%)$. The $\mathrm{HbE}$ values of $\mathrm{HbE}$ with $\alpha$ - Thalassemia were found to be below the $3 \mathrm{SD}$ value $(14.77 \%)$ of the mean of $\mathrm{HbE}$ level of HbE heterozygote (26.27\%), with few exceptions. However, in those cases where $\mathrm{HbE}$ values are within 3SD of mean of $\mathrm{HbE}$, the low hemoglobin level and the peripheral blood picture were suggestive of an associated Thalassemic abnormality. Again, the HbE levels of HbE- $\beta$ Thal were beyond the 3SD value $(37.77 \%)$ of the mean of the $\mathrm{HbE}$ heterozygote. This is in correlation with the study of Mais DD et $a^{(6)}$.

Only two cases of HbSE were encountered during the study period, the mean of sickle peak being $23.55 \%$ and $\mathrm{HbE}$ 9.75\%, with mean $\mathrm{HbF}$ peak being $4.9 \%$. The peripheral blood picture showed elongated cells, suggestive of the sickle abnormality. However, blood transfusion history was elucidated in these patients, so exact quantification of the different hemoglobin levels were not possible. Inclusion of more number of cases is required for further statistical analysis.

\section{Conclusion}

The present study identifies the range of different hemoglobin levels in $\mathrm{HbE}$ syndromes, particularly with reference to $\mathrm{HbA}_{2}$ level, which helps to detect associated abnormalities. The concurrent iron deficiency anaemia also needs to be kept in mind in dealing with a population where iron deficiency is very common. Genetic studies need to be performed, particularly in compound heterozygotes, to define the exact range of $\mathrm{HbE}$ levels with each gene deletion.

\section{Acknowledgements}

I want to thank my seniors and technical staff for their support. There is no conflict of interest declared.

\section{Reference :}

1. Kaushansky A, Lichtman MA, Beutler E , Kipps TJ, Seligsohn U, Prchal JT. editors. Williams Haematology. 8th ed. New York : McGraw-Hill Companies; 2010

2. Aggarwal S, Saluja S, Bhasin S, Sharma M, Gupta DK, Gupta B, Mittal V. HbE variants - Retrospective analysis in a tertiary care centre. J Indian Acad Clin Med 2011; 12(4): 263-265

3. Tyagi S, Pati HP, Choudhary VP, Saxena R. Clinico heemotological profile of $\mathrm{HbE}$ syndrome in adults and children. Haematology 2004; 9: 57-60

4. Deka R, Gogoi BC, Hundrieser J, et al. Hemoglobinopathies in northeast India. Hemoglobi. 1987; $11: 531-538$

5. Singh RM, Choudhury B, Singh TS. Hemoglobin E distribution in four endogamous populations of Manipur (India). Eurasian J Anthropol 2010: 1(2): 109-117

6. Mais DD, Gulbranson RD, Keren DF. The range of hemoglobin A2 in Hemoglobin $\mathrm{E}$ heterozygotes as determined by capillary electrophoresis. Am J Clin Pathol 2009; 132: 34-38

7. Vichinsky E. Hemoglobin E syndromes. Hematology Am Soc Hematol Educ Program 2007: 79-83 
8. Premawardhena A, Fisher CA, Olivieri NF, et al. Hemoglobin E $\beta$ Thalassaemia in Sri Lanka. Lancet 2005; 366: 1467-1470.

9. Mishra P, Pati HP, Chatterjee T, et al. Hb SE disease: a clinic - hematological profile. Ann Hematol 2005; 84: 667-670

10. Greer JP et al .editors. Wintrobe's Clinical Hematology. 12th ed. Philadelphia: Lippincott Williams \& Wilkins; 2009

11. Schroeder WA, Shelton JB, Shelton JR et al. The estimation of $\mathrm{HbA}_{2}$ in the presence of $\mathrm{HbC}$ or $\mathrm{HbE}$ by reverse phase high performance liquid chromatography. Hemoglobin 1986; 10: 253-257

12. Keren DF, Hedstrom D, Gulbranson R et al. Comparison of Sebia Capillarys electrophoresis with the Primus high - pressure liquid chromatography in the evaluation of hemoglobinopathies. Am J Clin Pathol 2008; 130: 824-831

13. Cotton F, Changying L, Fontaine B et al. Evaluation of a capillary electrophoresis method for routine determination of hemoglobins A2 and F. Clin Chem. 1999; 45: 237-243

14. Jenkins MA, Hendy J, Smith IL. Evaluation of hemoglobin A2 quantification assay and hemoglobin variant screening by capillary electrophoresis. J Capillary Electrophor 1997; 4: 137-143

15. Cotton F, Malaviolle X, Vertongen F, Gulbis B. Evaluation of an automated capillary electrophoresis system in the screening for hemoglobinopathies. Clin Lab 2009; 55 (5-6): 217-221

16. Cotton F, Wolff F, Gulbis B. Automated capillary electrophoresis in the screening for hemoglobinopathies. Methdods Mol Biol 2013; 984: 227-23
17. Keren DF, Hedstrom D, Gulbranson R, Ou C, Bak R. Comparison of S ebia Capillarys Capillary Electrophoresis With the Primus High - Pressure Liquid Chromatography in the Evaluation of Hemoglobinopathies. Am J Clin Path 2008; 130: 824-831

18. Winichagoon P, Svasti S, Munkongdee T, et al. Rapid diagnosis of thalassemias and other hemoglobinopathies by capillary electrophoresis. Transl Res. 2008; 152: 178-184

19. Rao S, Kar R, Gupta SK, Chopra A, Saxena R. Spectrum of hemoglobinopathies diagnosed by cation exchange HPLC \& modulating effects of nutritional deficiency anaemias from north India. Indian J Med Res 2010; 132: 513-519

20. Denic $\mathrm{S}$ et al. Hemoglobin $\mathrm{A} 2$ Lowered by Iron Deficiency and $\alpha$ - Thalassemia: Should Screening Recommendation for $\beta$-Thalassemia Change ISRN Hematol 2013: 1-5

21. Lim WF, Muniandi L, George E, Sathar J, The LK, Lai MI. $\mathrm{HbF}$ in $\mathrm{HbE} / \beta$-thalassemia: A clinical and laboratory correlation. Hematol 2015; 20 (6): 349-353

22. Charoenkwan P, Wanapirak C, Thanarattanakorn P, Sekararithi R, Sae - Tung R, Sittipreechacharn S, Sanguansermsri T. Hemoglobin E levels in double heterozygotes of hemoglobin E and SEA - type alpha - Thalassemia. Southeast Asian J Trop Med Public Health 2005; 36 (2): 467-70

23. Hafiza A, Malisa MY, Khirotdin RD, Azlin I, Azma Z, Thong MC et al. HbA2 levels in normal, beta - Thalassaemia and hemoglobin E carriers by capillary electrophoresis. Malays J Pathol. 2012; 34 (2): 161-4

*Corresponding author:

Abhijit Kalita, Address: House no 66, Happyvilla, Ujanbazar, Guwahati, Assam, India. Pin: 781003

Phone: +91 8811039142

Email: abhighy1985@gmail.com

Date of Submission : 25.12.2016

Date of Acceptance : 01.05.2017

Financial or other Competing Interests: None.

Date of Publication : 31.08.2017 